\title{
The Local Groundwater Balance Model: Stakeholders Efforts to Address Groundwater Monitoring and Literacy
}

Yolanda Lopez-Maldonado ${ }^{1,2^{*}}$, Eduardo Batllori-Sampedro ${ }^{3,4}$, Claudia R. Binder ${ }^{5}$, Brian D. Fath ${ }^{2,6}$

${ }^{1}$ Department of Geography, Ludwig Maximilian University of Munich, Luisenstrasse 37, Munich, 80333, Germany

${ }^{2}$ Advanced Systems Analysis Program, International Institute for Applied Systems Analysis. Laxenburg, A-2361, Austria

${ }^{3}$ Ministry of Urban Development and Environment of Yucatan. Calle 64 No. 437 Merida, Yucatan, 97000, Mexico

${ }^{4}$ Department of Human Ecology, Center for Research and Advanced Studies, Cinvestav-IPN. km 6 Antigua Carretera a Progreso, Merida, Yucatan, 97310, Mexico

${ }^{5}$ Laboratory for Human Environment Relations in Urban Systems, IIE, ENAC, Ecole Polytechnique Federal de Lausanne, EPFL. Lausanne, CH-1015, Switzerland

${ }^{6}$ Department of Biological Sciences. Towson University, Towson, MD 21252, USA

* Correspondence to: Yolanda.Lopez@geographie.uni-muenchen.de 


\title{
The Local Groundwater Balance Model: Stakeholders Efforts to Address Groundwater Monitoring and Literacy
}

\begin{abstract}
Understanding groundwater systems is crucial to ensure their monitoring and protection. Global groundwater models and predictive tools exist to better understand them. In view of scarce groundwater data especially in developing countries, the question of how to model these systems and make them usable for groundwater management is crucial. Herein, we demonstrate how a transdisciplinary process can overcome the data scarcity problem and lead to the development of a Local Groundwater Balance Model (LGBM). Over 50 actors from more than 15 disciplines and groundwater related sectors were involved for the case of Yucatan, Mexico. Results revealed high wastewater emissions to the aquifer discharged without treatment and poor recycling practices. The method can be adapted to specific regions, can be used to address methodological challenges for monitoring, and can contribute with the achievement of the 2030 Development Agenda by addressing Sustainable Development Goal 6, relatedTargets $(6.3,6.4,6.5,6.6(a, b))$.
\end{abstract}

Keywords: local groundwater balance model; sustainable development goals; groundwater balance; Yucatan; stakeholders. 


\section{INTRODUCTION}

\subsection{Groundwater: our complex common-pool resource}

Groundwater is an important common-pool resource that plays a unique role for human and ecological health and supports the freshwater needs of up to two billion people (Gleeson et al. 2012, Richey et al. 2015). Indeed, groundwater has been described as a key, strategic, socially important, primary, life-sustaining resource (Custodio 2002, Giordano 2009, Richey et al. 2015). However, groundwater management represents a societal challenge since problems of universal importance tend to occur at different levels and scales (e.g., human-hydrological and local-global) (Sophocleous 2002, Gleeson et al. 2016). Understanding groundwater characteristics and dynamics is crucial for its monitoring and protection, which requires data and cross-scale approaches to support communities to address urgent local environmental challenges.

In recent decades, there has been an increasing concern as human activities are placing excessive pressure on groundwater resources (Döll and Fiedler 2008, Vermooten and Kukuric 2009, Van Loon et al. 2016, Wada 2016). This has caused a reconsideration of groundwater as one of the major future concerns for humanity, and to include it into global agendas, publications (both scholarly and popular), and large-scale policy recommendations on the subject, where past water related targets were missing (UN-Water 2016, World Economic Forum 2016). In addition, as these concerns grow, the urgent need to ensure availability and sustainable management of water and sanitation for all remains crucial.

To date, hydrological issues are playing a key role in the implementation of the goals set in the 2030 Agenda for Sustainable Development, in which water has a crosscutting role linked to many other Sustainable Development Goals (SDG's) (UN- 
Water 2016). Water is interrelated to almost all remaining SDG's, making it a challenge to assess, monitor and support their implantation. Thus, with a dedicated water goal (SDG 6) on the sustainable development agenda, the need for data integration and monitoring remains essential to ensure the success of all the water related targets (UNWater 2016).

\subsection{Groundwater monitoring requires groundwater knowledge}

To monitor and enhance our understanding of groundwater and its problems, global models and monitoring initiatives exist (Sood and Smakhtin 2015, Wada 2016). These models and initiatives have mostly been applied for understanding global-hydrological processes, hence, their use and applicability to local groundwater systems is unclear. In view of data scarcity mostly in developing countries, a key challenge is how to model these systems and make them usable for better groundwater monitoring and consequent management.

Good groundwater management depends on how we use, manage and value the resource (Gleeson, Alley, et al. 2012). Successful monitoring and management often calls for a clear understanding of the groundwater system or groundwater literacy defined here as: the knowledge of the users about the resource and some of its attributes, and their perception and valuation of their impacts in the system. We argue that communities need to develop appropriately their monitoring tools and to produce information to use and monitor groundwater resources properly. Likewise, scientists and policy makers need to consider local conditions, knowledge, and norms to build local scale models since groundwater problems are largely local (Giordano 2009, Gleeson et al. 2016). However, it remains unclear how hydrologists, for example, can apply their results at a local scale and how they can significantly contribute towards groundwater literacy. 
The objective of this study is to develop a Local Groundwater Balance Model (LGBM) by quantifying flows and distribution of groundwater in a local aquifer and to influence groundwater literacy with the involvement of more than 50 stakeholders. Recognizing the importance of community participation and groundwater literacy is essential to address effectively SDG 6 and its water related targets: "Ensure availability and sustainable water management of water and sanitation for all". We use the example of Yucatan, Mexico, where groundwater is the only source of freshwater for the population, where water demands and problems are growing, and groundwater data remain limited. The LGBM could be used to determine the human induced flows affecting groundwater quality, to monitor water availability and withdrawals, and to promote improved allocations between users. The LGBM is complementary to current assessment methods such as the Groundwater Footprint Method (GFM) (Gleeson, Wada, et al. 2012) and the Regional Water Balance (RWB) (Binder et al. 1997), and it can be used to address methodological challenges for monitoring.

For developing the LGBM the following research questions were addressed: 1) How is the natural system structured? 2) What are the inputs, outputs, and groundwater flows in the system? 3) Which human factors might induce groundwater pollution at a local scale? 4) How can the information obtained with the LGBM be used at a local scale?

We show how the LGBM was developed, by involving stakeholders, and this can be taken as a platform for groundwater monitoring following a ladder approach. The results shows that, for the implementation of SDG 6, the LGBM specifically supports Targets $6.3,6.4,6.5$, and 6.6 ( $a$ and $b$ ). 


\section{METHODS}

\subsection{Case study region}

Yucatan is located in the southeast portion of Mexico and is embraced in the hydrological unit area of the Yucatan Peninsula Aquifer, which includes the states of Yucatan, Campeche, and Quintana Roo. The total area of Yucatan is $124,409 \mathrm{~km}^{2}$ and the population recorded in 2015 was 2,097,175 inhabitants (INEGI 2015). The aquifer is karstic and unconfined, except in the coastal zone (Bauer-Gottwein et al. 2011). The soil characteristics and its high permeability influence the amount of rainfall that can directly enter the aquifer. Permeability helps water to flow through the rocks and precipitation infiltrates into the subsurface. This phenomenon had strong effects in the resource, especially the formation of the underground channels connected and sinkholes that are widely spread throughout the area. Within the study area, the agriculture sector is the main water consumer. Current aquifer problems are high levels of organic matter, fecal organisms, residual chemicals such as detergents and pesticides, etc. in both, rural and urban areas (Pérez Ceballos and Pacheco Ávila 2004, Bauer-Gottwein et al. 2011). With the interest of developing a possible solution for the groundwater crisis in the region, a priority area for environmental protection was established in 2014: the Geohydrological Reserve (GR) zone (Pacheco Ávila et al. 2004). Its aim was to create a zone in order to secure the provision of water for the metropolitan region. The creation of the GR zone comprises five lines that facilitate the water management and protection in the region of incidence. It's aim is to encourage local population in the development of actions that might generate economic benefits, while achieving conservation and restoration of the ecosystems: 1) economic valuation of environmental services, 2) restoration and conservation of cenotes, 3) improvement of groundwater quality through integral waste management processes, 4) development of studies for a sustainable 
resource management, and 5) improvement of ecosystems services and water provision for the complete population.

Groundwater storage and flow occur in a karst aquifer with major cave systems, where groundwater flow is dominated by turbulent conduit flow (Graniel et al. 1999). The quality of groundwater is threatened in the Yucatan karstic region in general due to a high population growth, tourism infrastructure, coliform concentrations, and high density of nutrients. Nitrogen and phosphorus concentrations coming from anthropogenic origin through sewage percolation threaten the resource. The GR zone consists in 13 municipalities and is located within the Ring of Cenotes (Perry et al. 2009) (Fig. 1). The municipality of Tecoh was selected as a case study due to the availability information for the year of 2014 in relation to other local municipalities. Further descriptions of the Ring of Cenotes, the groundwater context and a general description of the study area are available in the Supplementary Material. Insert Figure 1 here

\subsection{Model overview}

The LGBM, as proposed here, was developed to obtain a water balance and to assess local-scale groundwater impacts. This will allow users to monitor the local groundwater system in an integrated manner and thus, support the implementation of the SDG 6. The LGBM was developed in five steps in an iterative process (Fig. 2).

Insert Fig. 2 here

For developing the model, we employed the Material Flow Analysis (MFA) method (Baccini and Bader 1996, Brunner and Rechberger 2004) because it assisted us to analyze, understand, and visualize the flows and exchanges of materials and energy with the environment (Ayres and Ayres 2002). It quantifies flows that raise 
environmental and health risk concerns (Huang et al. 2012). In general, MFA is a systematic assessment of the flows and stocks of materials within a system defined in space and time. It is a helpful tool to understand flows, stocks and processes of the human activities and the environment. One crucial characteristic of MFA is that can serve as a basis for sustainable regional material management and for developing monitoring programs (Binder 2007).

MFA has also been used to investigate hazardous materials for environmental risk assessment in water bodies such as lakes, rivers and reservoirs (Palmquist and Hanæus 2005, Schaffner et al. 2009, 2010, Chèvre et al. 2013). We followed five different steps according to the MFA procedure to build the LGBM (Baccini and Bader 1996).

To the best of our knowledge, there is no precedence of a similar study in the literature; thus, for the development of the MFAs and the sets of diagrams, we started with the creation of an initial system analysis of the defined study area as described in section 2.1, based on expert opinion (see Supplementary Material). Then, the stakeholders were asked to (i) develop the system analysis; (ii) provide data on the flows and related sources; and, (iii) validate results in an iterative process by comparing the initial diagrams. Based on these data the LGBM was elaborated and related to a regionalized groundwater balance. We accounted for groundwater human induced flows by combining system analysis, mass balance, data estimation, expert and public consultation. The five steps to construct the LGBM are:

(1) System boundary definition: In the first step, a system boundary was defined in space and time (Baccini and Bader 1996, Binder et al. 1997). The hydrological system boundary is the GR zone in Yucatan, which includes thirteen municipalities located within the Ring of Cenotes, whereas the aquifer and atmosphere were located outside the system boundary. The flows of 
groundwater into, out of, and through the system boundaries were analyzed. The municipality of Tecoh $(16,200$ inhabitants) was selected as the study area to apply the method. Tecoh is part of the recharge zone of the GR zone and receives pollutants from intensive agriculture, particularly from southern parts of the state (Polanco Rodríguez et al. 2015). The same processes selected for the system analysis were used for the water balance with the analysis performed for the year 2014 .

(2) Identification of relevant flows, processes, and stocks: In the second step, five relevant processes: extraction, distribution, uses, treatment, and recycling were identified, defined, and validated in workshops with stakeholders working within the water sector. The stakeholders were given the first draft of the system analysis, which was previously developed by the authors as described in step 1 . Stakeholders were asked whether the processes and flows identified were in their experience correct. Following this, they were asked to fill in missing information, values and were also the basis knowledge for all the flows (For a detailed overview of the system analysis approach used during the research process see Supplementary Material). Five processes (extraction, distribution, uses, treatment, and recycling) were identified and a total of 39 flows were established. Groundwater was the substance used for the water balance. The aquifer and atmosphere were located outside the system boundary.

(3) Substance flow diagrams: In the third step, we developed substance flow diagrams by combining system analysis from the gathering of local and scientific knowledge.

(4) Water balance: In the fourth step, the water balance was estimated. The water supply company, Junta de Agua Potable y Alcantarillado de Yucatan (JAPAY), 
supplies water to $90 \%$ of the urban households. Rural households are water selfsufficient but they receive technical support from JAPAY. In addition to this, municipalities also receive water for a main pumped source that consists of legal concessions available for those who want to extract water for several uses from the aquifer. Tecoh, similar to the other 105 state municipalities, has only one main water source: the groundwater system. It also means that water can be extracted from local wells and stored in tanks without a concession from Conagua (National Water Commission). Groundwater is pumped directly to the households, and this transportation process has an estimated efficiency of $60 \%$. In general, most rural households also extract water from their own wells, locally called pozos. Calculations were made considering one year (2014) since it was the year with most available and reliable statistical data. We estimated the groundwater balance as the sum total of inputs, stocks, and output flows. First, we selected primary sources of information about the total extracted water volume based on national and regional statistics. Expert consultation was made to get local data as proposed by some authors (Gleeson et al. 2012). We then calculated flows at local scale and the associated outputs (see Supplementary Material).

(5) Interpretation of results. In the fifth step, the results obtained were interpreted and the method was adapted to be applied in further sectors (e.g., the livestock and industry sector). With the aid of Sankey diagrams within each sector, obtained using STAN software (Cencic and Rechberger 2008), the Sankey flows depicted the directed outputs of the human system to the aquifer and thus indicated how human activities influence the system. One essential characteristic of this tool is that any substance or material can be represented by arrows, whose 
width are shown proportionally to the flow quantity and the transfers between processes (Schmidt 2006). Uncertainty values were not considered in the model due to the lack of sufficient data (uncertainties of only 2 out of 39 flows are known).

\subsection{The Local Groundwater Balance Model}

There are four sectors in the model: 1) industry, 2) agriculture, 3) livestock, and 4) households, and five relevant processes (Table 1). It starts with the groundwater storage component, which accounts the subterranean flow. Then fluxes of groundwater for each sector were calculated simultaneously.

Insert Table 1 here

\subsection{Data sources}

In Tecoh, and most of the Yucatan's 106 municipalities, time series data on social and natural resources are very poor in terms of coverage, accuracy, and duration. This is maybe due to government terms reasons and the related changes on governmental parties. Thus, data were obtained and derived from different sources: literature, national and local statistics, stakeholder workshops, expert opinions and consultation, and local interviews (Table 2). Literature and information at the country level were reviewed including national policies, reports, yearbooks and scientific publications. Online interviews were performed to consult experts and members from the water sector (Krueger et al. 2012). We used expert open-ended interviews and informal conversations with stakeholders, as well as in-situ observations in the municipality selected (Creswell 2003).

Insert Table 2 here 
In addition, interviews and expert consultation were obtained during workshops performed in 2014. Stakeholders working in the water sector were asked about data regarding specific sectors and the system analysis was validated with representatives from regional and local level. More than 50 stakeholders were involved (for further characteristics of the interviews see Supplementary Material). The scientific community were actively involved in general discussion and exchanged opinions with other sectors by stimulating and valorizing contradictory ideas. Stakeholders were able to develop strategies and possible solutions for the problem of groundwater monitoring in the region. Along with the LGBM, interviews with members and experts working in the water sector, NGO's, and stakeholders other than the former group of stakeholders were performed. With this we promoted the engagement of the population and developed on existing methodologies towards a monitoring built on stakeholders efforts.

As shown in Table 2, we determined the most representative socio-economic sectors from data obtained during workshops, statistics, and literature. To obtain information about groundwater extraction from wells located in rural households, we interviewed members from the water sector. Simplifications and assumptions were made to determine groundwater extractions more accurately for the year 2014, since extractions might occur due to the large amount of rural household wells. Data regarding the number of local wells were obtained through interviews and local expert consultations. The transfer coefficients of each process were established from diverse data sources (described in the Supplementary Material).

\subsection{Modeling procedure}

The model was set up for the year 2014 by using STAN 2.0. It starts with the groundwater storage component, which accounts the subterranean flow. Then fluxes of groundwater for each sector were calculated simultaneously. Each sector was modelled 
and described by applying the steady-state overall mass balance equation (1):

$$
\sum E_{i}-\sum S_{i}=0
$$

Where $E_{i}$ is the $\mathrm{i}^{\text {th }}$ input flow, and $S_{i}$ is the $\mathrm{i}^{\text {th }}$ output flow.

\section{RESULTS}

We show, how in a transdisciplinary process, the data scarcity problem can be overcome and a LGBM can be developed. Over 50 stakeholders from more than 15 disciplines and groundwater related sectors (scientists, policy-makers, NGO's, students, divers and local members) were involved in obtaining a groundwater balance for the Municipality of Tecoh in Yucatan, Mexico. The results of the application of the LGBM are presented in the following order: 1) System analysis including relevant flows, processes and stocks, 2) Water balance, and 3) the interpretation of substance flows including inputs, outputs and total flows within the system.

\subsection{System analysis}

Figure 3 illustrates the system analysis for the Municipality of Tecoh, GR zone, year 2014.

Insert Figure 3 here

Input flows to the system are precipitation and import of drinking water; the output flows are evaporation and groundwater discharges. The system is composed of 5 relevant processes as listed in Table 1: Extraction, Supply/distribution, uses/consumption by all the sectors, treatment/management (e.g., Biodigestion), and recycling. Our model also includes water losses estimated through soil percolation. Input flows to the system are: precipitation and water inputs from the ocean; the major 
output flows are evaporation and groundwater discharges.

Water enters the system through precipitation (Precipitation), by the water supply company JAPAY (Repda supply) which draws groundwater directly from the system, as well as imports of water and direct extractions from private wells located on rural and urban households (Direct Extraction), drinking water bottles (Drinking) and tanks (Tanks) which serve as additional collected private groundwater extractions. During the potable water transport (Main Inputs) for its distribution from the Repda supply to the consuming sectors, a quantity of water is lost due to damage in the pipes. Water is consumed by households (accounted as Home, and Patio, vide infra), agriculture (accounted as Agriculture Irrigation, and Agriculture Seasonal, vide infra), livestock (Livestock), and industry (Industry Tortilla), summarized under Sectors combined in Figure 3. Water is either treated in a biodigestion plant $(S L A)$, retained within a commodity (e.g., tortillas) (Vapour loss, and $W$ in TTT), directly sent to the groundwater (To Groundwater), or lost through evapotranspiration (Evapotranspiration).

\subsection{Water mass balance}

Figure 4 shows the numerically-solved water mass balance. It accounts for Tecoh municipality in the GR zone for the year 2014. The total amount of water entering the system is $32,217,002 \mathrm{~m}^{3}$ year $^{-1}$, whereas the largest input flow is precipitation accounting for $77.6 \%$ of the inputs, followed by Repda supply $15.8 \%$, Tanks $4.4 \%$, Direct Extraction 2.2\%, and less than $0.001 \%$ for Drinking.

Insert Figure 4 here

A quantity of $17,633,000 \mathrm{~m}^{3}$ year $^{-1}$ from the Precipitation reaches agricultural soils (Agriculture Seasonal and Agriculture Irrigation) and provides 91.2\% of the water 
needed in this sector. Three sources of water are used for irrigation (Agriculture Irrigation): from precipitation (Precipitation AI), Repda (Repda A), and a small contribution from a recycled source (SLA from Biodigestion) (as seen in Figure 4). However, they only account for $9.5 \%$ of the total water supply. Consumption of water from households (Home and Patio) and pig farms (Livestock) account for 10.5\% and $0.4 \%$ of the total water consumed, respectively.

The largest output flow is evaporation (Evapotranspiration and Vapour loss) accounting $80 \%$ of the water leaving the system. From all water consumed, only less than $0.04 \%(Y 1)$ of the wastewater is treated and re-used in another subsequent process $(S L A)$. The rest of the wastewater from Households ( $W W H$ and $W W S)$, septic tanks $(W W$ to $W L$ ), agricultural outputs ( $S A 1$ and $S A 2)$, pig farms (Small Farms), and tortilla industry (SIn) flow into the aquifer without any treatment. It was stated that the different sectors contribute as follows to the contamination of the aquifer: the agricultural and livestock sector, which might contain high concentrations of pesticides and organic matter (i.e., discharges from pig farms) accounting for $c a .19 .4 \mathrm{hm}^{3} \mathrm{year}^{-1}$, followed by tortilla industry (high $\mathrm{pH}$, alkaline discharges) accounting for $c a .5,700 \mathrm{~m}^{3}$ year $^{-1}$. The flows of wastewater from households to the aquifer amount to $c a .11 .3 \mathrm{hm}^{3} \mathrm{year}^{-1}$. As mentioned above all wastewater emissions are discharged directly into the aquifer without treatment as demonstrated by the poor treatment and recycling practices $(<1 \%$, relative to the total waste water produced).

\subsection{Interpretation of substance flows}

Results revealed: a) high wastewater emissions into the aquifer (ca. $6.4 \mathrm{hm}^{3}$ year ${ }^{-1}$ ). Wastewater ranges from grey water to wastewater with high concentrations of organic matter (i.e., discharges from pig farms) and alkaline discharges (i.e., tortilla industry); b) all wastewater emissions are discharged directly into the aquifer without treatment; 
and c) poor recycling practices $(<1 \%$, relative to the total water emissions).

When considered by sector, flows displayed the following characteristics:

- Household: In the household sector the major consumption is represented by water storage in tanks (Tanks). This volume is approximately 3 times larger than from direct extraction from wells (Direct extraction $H$ ) and 1.5 times larger than from the Repda water supply (RepdaH). Septic tanks ( $W W$ to $S T$ ) eventually provide some treatment to wastewater emissions from Households (Home), but our results clearly show that this water is discharged to the aquifer and is not used in another subsequent process. In the Household sector (Home) $75 \%$ of the wastewater goes to septic tanks (Septic Tank) and the remainder is discharged directly into the aquifer $(W W H)$.

- Agriculture: Results shows that $60 \%$ of all input water is used for agricultural practices. The model does not consider irrigation based on seasonal periods. Note that the treated water $(<1 \%$, from Biodigestion, vide infra) is used for irrigation $(S L A)$.

- Livestock: One particularity is the livestock sector, where small farms generate 10 times more wastewater than the larger farms. It is noticeable that discharges from small farms (Small farms) are also direct outputs into the aquifer without treatment. In contrast, wastewater from large farms $(Y 1)$ is treated in Biodigestors (Biodigestion), after which this water is reused $(S L A)$ in other subsequent process (Agriculture Irrigation). Small farm process output (Small Farms) and wastewater emissions from the tortilla industry (SIn) are minor flows $(3.8 \%$ and $0.02 \%$, relative to the total wastewater flows to the aquifer, respectively), but they are discharged directly into the aquifer without any treatment. 
- Industry: During workshops, participants were more concerned about the industry sector (Industry). They were aware of the challenges faced due to the lack of data about the processes involved and local and regional statistics. For these reasons and the lack of data for the industry sector in general, we selected the tortilla industry to illustrate this sector partly because an estimation of the water involved in the entire production process is possible to carry out by considering statistical information and the virtual water contained, and because it is well known from previous unpublished reports and interviews with experts, that these effluents are heavily contaminated. In contrast to domestic, livestock, and agriculture, water mass balance for the tortilla industry was obtained by considering its production processes, i.e., alkaline hydrolysis, nixtamal washing, and baking. Virtual water in tortilla final products was considered only as an example and starting point for the calculations. More details about the flows, definitions, and calculations can be found in the Supplementary Material. Importantly, albeit the total water consumption of this sector represents $0.023 \%$ from the total water input in the balance, all the outputs from the sector constitute a $77 \%$ (SIn relative to $E I n$, ca. $\left.5,700 \mathrm{~m}^{3} \mathrm{year}^{-1}\right)$ of wastewater with high $\mathrm{pH}$ and high content of organic matter, and this water is directly discharged into the aquifer.

\section{DISCUSSION}

Groundwater in Yucatan is needed for almost all purposes, including health, food, and industrial production. Thus, groundwater pollution may have different origins and may generate different wastewater. With little coordination among users and government, its monitoring, can be a challenge. In this paper, we analyzed, in a unique way, groundwater resources, in a place where no rivers exist on the surface. Our approach 
was to analyze the main socioeconomic sectors including different uses and users. Built on local monitoring efforts, the data scarcity problem was overcome and the LGBM developed. The LGBM supports the current global monitoring framework of SDG 6 and contributes towards groundwater literacy.

\subsection{The Local Groundwater Balance Model as a coherent mechanism for monitoring}

Investigation of flows and development of the first LGBM in Yucatan, revealed high wastewater emissions into the aquifer $\left(c a .32 \mathrm{hm}^{3}\right.$ year $\left.{ }^{-1}\right)$ that could be expected from anthropogenic sources. Obtained data are interpreted as reflecting:

(1) Extraction of groundwater: this process represents a central issue in the system since there are currently several gaps on water extraction regulations. The LGBM corroborates that significant volume is extracted directly from individual pumping from wells for domestic uses.

(2) Rapid recharge of rainwater: rainwater circulated in the system but this water is not collected for further use.

(3) Recycling: despite the poor recycling practices, the recycled wastewater final emissions are also directed into the aquifer $(<1 \%$, relative to total water emissions).

(4) Management of groundwater: results from the model regarding uses illustrate the disparity among sectors and it shows the main extractors and polluters; however, due to the complexity of the household sector it requires further investigation.

(5) Rapid rainwater recharge is an important event as can be seen in the model. The agricultural sector may circulate some hazardous substances present in open areas, at least during rainy seasons. 
(6) This study also indicates that there is a poor wastewater treatment infrastructure, which leads to a generalized introduction of pollutants into the aquifer.

The obtained results, even in a small and well-defined system such as the GR zone, show that flows and pollution sources are difficult to determine. Our results provide critical insights for future analyses since they do not depend on published data: we obtained them through workshops with stakeholders and with a combination of research tools from a variety of disciplines. Although uncertainties and gaps persist, our results are clear: the LGBM allows the identification and assessment of the human induced flows affecting the quality of groundwater resources of an individual local aquifer with more precision, together with the society, while demonstrating that this model can be combined with other methods (such as MFA) and include virtual water calculation.

The LGBM could be extended in the following directions: 1) model the flux of hazardous substances within the system under different scenarios, and 2) to incorporate the dynamic nature of decision-making into modeling. Monitoring, back-casting, and modification of resource with future research data are highly recommended.

\subsection{Step-by-step: local monitoring of SDG 6.}

To "Ensure availability and sustainable management of water and sanitation for all", according to the SDG 6, there is a need to monitor eight different interrelated targets globally. At present, there are several global tools and initiatives for water monitoring (WHO/UNICEF Joint Monitoring Programme for Water Supply and Sanitation/JMP, and UN-Water Global Analysis and Assessment of Sanitation and Drinking Water/GLAAS). A prerequisite for the implementation of these initiatives is to have a thorough knowledge of the system and simultaneously a consistent database, usually collected at a country and global scale worldwide (UN-Water 2016). However, this is 
not the case in less developed countries where databases are not often reliable.

Groundwater monitoring is often a difficult task due to the cost, complexity and unpredictable nature of the system. In the case of Yucatan a coherent framework for monitoring groundwater from a local perspective is required. To pursue global or national monitoring, while considering local actions and monitoring efforts, the LGBM combines existing monitoring initiatives such as country base data to analyze the structure of a local system, the relevant flows, and the main socio-economic sectors.

The obtained results can be used by the involved stakeholders to: i) identify the human induced flows affecting groundwater quality, ii) to monitor water availability and withdrawals, iii) to promote improved allocations between users, and iv) to stimulate water recycling, traditional rainwater harvesting practices and use efficiency.

A summary of the main SDG 6 targets and indicators that can be addressed with the development and application of the LGBM is provided in Table 3. To implement SDG 6, the LGBM specifically supports the following Targets 6.3, 6.4, 6.5, and 6.6 (a \& b) by: facilitating examination of hotspots of pollution, distribution of flows of hazardous substances, minimizing release of chemicals, ensuring sustainable withdrawals, revealing water extraction trends and sectors with major consumption, strengthen participation of local communities, and to protect the ecosystem. As an example, in the case of Tecoh, concentrations of $6.5 \mathrm{ppm}$ of $\alpha$-lindane and $10.9 \mathrm{ppm}$ of $\delta$-lindane were found directly from local wells and sinkhole samples in an area with 724 agricultural production units (ca. 4000 hectares) (Polanco Rodríguez et al. 2015). These values are above the permitted concentration limits, according to Mexican Norms. It is reasonable to assume that further substances can also be found in the surrounding area. With the development of the LGBM it would be possible to determine the flows of those substances within a particular pre-defined system. 
Insert Table 3 here

Using the example of Target 6.3, the indicator 6.3.1 addressed the proportion of all wastewater generated that is safely treated at source or through a treatment plan before it is discharged into the environment. In the case of Yucatan, and particularly in rural areas, the percentage of the population with safely treated wastewater is uncertain since some households do not have a treatment facility, a septic tank, or latrine pits and inhabitants do not tend to handle (or are not allowed to) and re-use the wastewater (e.g., as an agricultural input). The LGBM shows that, despite a portion of wastewater reaching a treatment plant, another portion remains untreated and the emissions are outputs discharged directly into the environment. As already suggested by several studies, these emissions come in a variety of contaminants such as: organic matter, pesticides, pharmaceuticals, etc. (Metcalfe et al. 2011).

From a water quality and environmental perspective, this is remarkable because it might bring critical problems to the population's health and biodiversity. In policy terms, the LGBM might provide policy relevant guidance to government and environmental authorities for implementing measures intended at mitigating impacts on the resource. Although there are suggestions for the use of tools and methodologies to validate and verify the treatment data, including geospatial information and earth observations (UN-Water 2016), their applicability in groundwater systems remains complex. Recent technologies such as GRACE (NASA 2016) are appealing for this geospatial monitoring purpose but its global applicability is yet to be implemented.

The Integrated Monitoring Guide for SDG 6 suggests that it is necessary to collect data from different locations of both urban and rural settings in order to capture the full range of scenarios needed for national estimates. However, in general, data are obtained through detailed questionnaires filled in by experts and consultants who collect 
information, but this can generate high levels of uncertainty. It is also recommended that organizations and institutions should be consulted for the assessments including officials responsible for sanitation, external agencies and organizations responsible for regulation or licensing treatment services. Nevertheless, these data still remain a part of global and regional estimates and include some sectors in particular.

As proposed by the Integrated Monitoring guide for SDG 6, it is possible to obtain data from databases of typically involved institutions, ministries, and establishments but the lack of reliable data in Latin-American countries might generate uncertainties that can be crucial when calculating the flows (Binder et al. 1997). In Yucatan for example, ownership of data is a critical issue since current water management does not overlap and some information is not published in scientific literature and lacks credibility in some sectors (according to Espejo, W. personal communication, 19, December 2014).

\subsection{The LGBM supports groundwater literacy}

A more systemic understanding of scale interdependencies of water systems is needed globally. In Yucatan, groundwater is currently the main source of freshwater for the population but knowledge of the state of the system is limited. Results obtained via informal conversations with stakeholders during workshops show that crucial information about the system (e.g., precise location, quantity, main fluxes and function), was poorly understood by the majority of the participants. Identifying major flows, by applying system analysis and tendencies with the stakeholders, help us to understand the system dynamics and to influence their groundwater literacy. The LGBM helps to explore, develop, represent and use this information to assess human impacts, and this can be the basis for a future groundwater management in the region. 
To implement monitoring of SDG 6 it is crucial that data collection, analysis, and dissemination involve stakeholders and government. Current mechanisms in this regard range from household surveys to global earth observations. However, this does not tend to influence the knowledge of the users since most of the surveys and specialists collect the data on particular fields. The LGBM provides a systematic framework to identify all of the relevant stakeholders and consider their participation in the decision making process since we include social science methods. The elaboration of the LGBM included a wide range of stakeholders across sectors and levels of government.

Workshops were crucial because stakeholders were able to interact, share data and to be involved in the same degree of participation. Through this overall participation, the first groundwater model was developed and every step for its construction was validated. Our estimates are consistent with previous estimates conducted decades ago within the region (Villasuso and Méndez Ramos 2000) but our analysis is stronger since information was obtained directly from stakeholders currently working in the water sector.

Whereas the methodology for determining hydrological flows and water balance on aquifers and water bodies is already internationally standardized within proper methods (Molden 1997), and that global groundwater models do not consider the impact of economic forces (in terms of human interventions) on hydrology, several uncertainties arise (Chahine 1992, Sood and Smakhtin 2015). Through cooperation, our results demonstrate how it is possible to work together and to simultaneously narrow the gap between science, policy-making, and society.

Our case is so far completely different in terms of obtaining more empirical results, which in turn might contribute towards more real solutions. We argue that 
groundwater models can contribute with the velocity of data processing, understanding characteristics of global groundwater resources, its distribution, volumes, fluxes, and scrutinizing the interrelated human impacts. However, the rate at which we decided to take local actions and to find alternatives to effectively address groundwater problems are crucial. The LGBM offers the possibility to involve local people and work towards groundwater literacy. We collected data during different fieldwork research stages from 2013 to 2017 and validated them during workshops with experts working in the water sector and local population. The novelty of this work is that our complete methodology produces systematically useful results, strengthens participation of local communities, and recognizes local knowledge as an informal norm of monitoring. Interviews and informal conversations with experts and locals were carefully designed, which guarantees a certain structure in the answers. This provides the opportunity for interviewees to freely respond and to make use of their knowledge on particular topics. The interviews provided information that can be compared with data published in the literature, so its validity and reliability can also be anticipated. In our case, participants were able to develop, use, and share their own knowledge to start to solve their own problems.

Gleeson et al. (2012) have proposed that multigenerational goals (50-100 years) for water quantity and quality be set for many aquifers. Additionally, short time policy horizons should be implemented by back-casting for pre-established sustainable goals. Thus, we agree with the importance of models; however, communities can no longer wait for models to solve urgent water problems. The practical aim is simple: models can help to make predictions of the hydrological cycle to support environmental management, and, furthermore, they can meaningfully contribute towards solutions if they involve stakeholders. 


\section{CONCLUSIONS}

Yucatan has a large aquifer that is shared by local communities. In several of them, the situation can be seemingly positive with no current reported pollution or water use conflicts. However, groundwater requires detailed analysis and planning and this applies to areas related to several users and uses, particularly those that are vulnerable to contamination.

Sustainable Development Goal 6 is about drinking water, and drinking water in Yucatan is obtained mainly from groundwater. Large global-scale modeling is crucial in evaluating groundwater resources. Analyzing groundwater using a Local Groundwater Balance Model provides a starting point for detailed analysis of the effect of anthropogenic emissions on natural groundwater processes. This is critical for policy and management implications, particularly in a place where no other sources of freshwater exist. Monitoring at each step and by particular socioeconomic sectors of the chain helps to capture the hotspots generated by users, including the fraction that is

reused or treated. Our confidence is attained not only due to mathematical equations but also from results obtained during stakeholder workshops.

The systematic development of knowledge of the groundwater system is necessary. However, despite a deficient knowledge base, the analysis must be started using the current available knowledge of the local population and the different sectors. The LGBM has been useful by raising concerns over the environmental destination of hazardous materials. It indicates that perhaps it is not enough to know about the potential hazards of those substances, and that moving them from the different compartments may cause future consequences. The visual representation of inflows, outflows, abstraction, and returns will support the understanding of the system and thus will facilitate the future management of groundwater. As our project is related to policy 
makers, our results could be easily implemented to plan the transition process for better groundwater management within the region.

Our results are innovative and it constitutes a versatile methodology that can be applied in regions with similar characteristics. It can be a useful tool for resource management considering poor data and it is aimed at knowledge integration as key for understanding social-ecological systems. The ideas proposed here may guide the adoption of a new approach towards a better groundwater resource management. This will support a future groundwater balance for the complete region by adapting particular parameters into the model. We agree with the importance of models, but we offer a much more favorable view of systems-analytical approach to groundwater resources.

The LGBM can be adapted to specific regions, can be used to address methodological challenges for monitoring and can contribute with the achievement of the 2030 Development Agenda. The LGBM can be built on existing monitoring frameworks and statistical standard definitions, classifications and treatment categories such AQUASTAT and SEEA.

Acknowledgments Part of the material in this paper was presented at the $12^{\text {th }}$ Kovacs Colloquium Water-related Sustainable Development Goals (SDGs) implementation: Knowledge, data, indicators, tools \& innovations, UNESCO, IAHS. We thank to the stakeholders, local communities and further participants that voluntarily involved in this research. Many thanks to the Ministry of Urban Development and Environment of Yucatan (SEDUMA) for their support for the development of workshops. YLM is grateful to J. Ayuso for his helpful discussions, and to J. Dunsford for the manuscript revision. Part of the research was developed during the Young Scientists Summer Program 2015 at the International Institute for Applied Systems Analysis, Laxenburg (Austria). Financial support was provided by the National Council of Science and Technology (Conacyt), Mexico (PhD scholarship No. 312243) and by the Potsdam-Institute fur Klimafolgenforschung e.V., Germany. Fieldwork expenses were covered by the Rachel Carson Center for Environment and Society, LMU, Munich. The authors declare no competing financial interest. 
Additional information is available in the online version of the paper (common term definitions, model description and development, full list of stakeholders, etc.).

\section{REFERENCES}

Ayres, R.U. and Ayres, L.W., 2002. A handbook of industrial ecology. Bodmin, Cornwall: Edward Elgar Publishing.

Baccini, P. and Bader, H.-P., 1996. Regionaler stoffhaushalt. Erfassung, bewertung und steuerung. Heidelberg: Spektrum Akademischer Verlag.

Bauer-Gottwein, P., Gondwe, B.R.N., Charvet, G., Marín, L.E., Rebolledo-Vieyra, M., and Merediz-Alonso, G., 2011. Review: The Yucatán Peninsula karst aquifer, Mexico. Hydrogeology Journal, 19 (3), 507-524.

Binder, C., Schertenleib, R., Diaz, J., Bader, H.-P., and Baccini, P., 1997. Regional Water Balance as a Tool for Water Management in Developing Countries. International Journal of Water Resources Development, 13 (1), 5-20.

Binder, C.R., 2007. From material flow analysis to material flow management Part I: social sciences modeling approaches coupled to MFA. Journal of Cleaner Production, 15 (17), 1596-1604.

Brunner, P.L. and Rechberger, H., 2004. Practical handbook of material flow analysis. Boca Raton, Florida: CRC Press LLC.

Cencic, O. and Rechberger, H., 2008. Material Flow Analysis with Software STAN. Journal of Environmental Engineering and Management, 18 (1), 3-7.

Chahine, M.T., 1992. The hydrological cycle and its influence on climate. Nature, 359 (6394), 373-380.

Chèvre, N., Coutu, S., Margot, J., Wynn, H.K., Bader, H.-P., Scheidegger, R., and Rossi, L., 2013. Substance flow analysis as a tool for mitigating the impact of pharmaceuticals on the aquatic system. Water Research, 47 (9), 2995-3005.

Creswell, J., 2003. Research design: Qualitative, quantitative, and mixed method approaches. Thousand Oaks, California: SAGE Publications.

Custodio, E., 2002. Aquifer overexploitation: what does it mean? Hydrogeology 
Journal, 10 (2), 254-277.

Döll, P. and Fiedler, K., 2008. Global-scale modeling of groundwater recharge. Hydrology and Earth System Sciences, 12 (3), 863-885.

Giordano, M., 2009. Global Groundwater? Issues and Solutions. Annual Review of Environment and Resources, 34 (1), 153-178.

Gleeson, T., Alley, W.M., Allen, D.M., Sophocleous, M.A., Zhou, Y., Taniguchi, M., and VanderSteen, J., 2012. Towards Sustainable Groundwater Use: Setting LongTerm Goals, Backcasting, and Managing Adaptively. Ground Water, 50 (1), 1926.

Gleeson, T., Befus, K.M., Jasechko, S., Luijendijk, E., and Cardenas, M.B., 2016. The global volume and distribution of modern groundwater. Nature Geoscience, 9, $161-167$.

Gleeson, T., Wada, Y., Bierkens, M.F.P., and van Beek, L.P.H., 2012. Water balance of global aquifers revealed by groundwater footprint. Nature, 488 (7410), 197-200.

Graniel, C.E., Morris, L.B., and Carrillo-Rivera, J.J., 1999. Effects of urbanization on groundwater resources of Merida, Yucatan, Mexico. Environmental Geology, 37 (4), 303-312.

Huang, C.-L., Vause, J., Ma, H.-W., and Yu, C.-P., 2012. Using material/substance flow analysis to support sustainable development assessment: A literature review and outlook. Resources, Conservation and Recycling, 68, 104-116.

INEGI, 2015. Instituto Nacional de Estadística y Geografía [online]. Censo General de Poblacion y Vivienda. Available from: http://www.inegi.org.mx/ [Accessed 9 Nov 2016].

Krueger, T., Page, T., Hubacek, K., Smith, L., and Hiscock, K., 2012. The role of expert opinion in environmental modelling. Environmental Modelling \& Software, 36, 4 18.

Van Loon, A.F., Gleeson, T., Clark, J., Van Dijk, A.I.J.M., Stahl, K., Hannaford, J., Di Baldassarre, G., Teuling, A.J., Tallaksen, L.M., Uijlenhoet, R., Hannah, D.M., Sheffield, J., Svoboda, M., Verbeiren, B., Wagener, T., Rangecroft, S., Wanders, N., and Van Lanen, H.A.J., 2016. Drought in the Anthropocene. Nature Geoscience, 9 (2), 89-91. 
Metcalfe, C.D., Beddows, P.A., Gold Bouchot, G., Metcalfe, T.L., Li, H., and Van Lavieren, H., 2011. Contaminants in the Coastal Karst Aquifer System Along the Caribbean Coast of the Yucatan Peninsula, Mexico. Environmental Pollution, 159 (4), 991-997.

Molden, D., 1997. Accounting for water use and productivity. Colombo, Sri Lanka: International Irrigation Management Institute.

NASA, 2016. GRACE Tellus Gravity Recovery \& Climate Experiment [online]. Available from: http://grace.jpl.nasa.gov/ [Accessed 10 Nov 2016].

Pacheco Ávila, J., Calderón Rocher, L., and Cabrera Sansores, A., 2004. Delineación de la zona de protección hidrogeológica para el campo de pozos de la planta Mérida I, en la ciudad de Mérida,Yucatán, México. Ingeniería, 8 (1), 7-16.

Palmquist, H. and Hanæus, J., 2005. Hazardous substances in separately collected greyand blackwater from ordinary Swedish households. Science of The Total Environment, 348 (1), 151-163.

Pérez Ceballos, R. and Pacheco Ávila, J., 2004. Vulnerabilidad del agua subterránea a lacontaminación de nitratos en el estado deYucatán. Ingeniería, 8 (1), 33-42.

Perry, E., Paytan, A., Pedersen, B., and Velazquez-Oliman, G., 2009. Groundwater geochemistry of the Yucatan Peninsula, Mexico: Constraints on stratigraphy and hydrogeology. Journal of Hydrology, 367 (1-2), 27-40.

Polanco Rodríguez, A.G., Navarro Alberto, J.A., Solorio Sanchez, J., Mena Rejón, G.J., Marrufo Gómez, J., and Del Valls Casillas, T.A., 2015. Contamination by organochlorine pesticides in the aquifer of the Ring of Cenotes in Yucatán, México. Water and Environment Journal, 29 (1), 140-150.

Richey, A.S., Thomas, B.F., Lo, M.-H., Reager, J.T., Famiglietti, J.S., Voss, K., Swenson, S., and Rodell, M., 2015. Quantifying renewable groundwater stress with GRACE. Water Resources Research, 51 (7), 5217-5238.

Schaffner, M., Bader, H.-P., and Scheidegger, R., 2009. Modeling the contribution of point sources and non-point sources to Thachin River water pollution. Science of The Total Environment, 407 (17), 4902-4915.

Schaffner, M., Bader, H.-P., and Scheidegger, R., 2010. Modeling the contribution of pig farming to pollution of the Thachin River. Clean Technologies and 
Environmental Policy, 12 (4), 407-425.

Schmidt, M., 2006. Der Einsatz von Sankey-Diagrammen im Stoffstrommanagement, Beiträge der Hochschule Pforzheim Nr. 124. Pforzheim: Hochsch.

Sood, A. and Smakhtin, V., 2015. Global hydrological models: a review. Hydrological Sciences Journal, 60 (4), 549-565.

Sophocleous, M., 2002. Interactions between groundwater and surface water: the state of the science. Hydrogeology Journal, 10 (1), 52-67.

UN-Water, 2016. Integrated Monitoring Guide for SDG 6 [online]. Available from: http://www.unwater.org/publications/publications-detail/en/c/434399/ [Accessed 15 Jan 2017].

Vermooten, S. and Kukuric, N., 2009. Collecting aggregated groundwater data to identify highly stressed aquifers worldwide. In: Trends and Sustainability of Groundwater in Highly Stressed Aquifers, Proceedings of Symposium JS.2 at the Joint IAHS and IAH Convention. Hyderabad, India: IAHS Publ. 329, 277-284.

Villasuso, M.J. and Méndez Ramos, R., 2000. A conceptual model of the aquifer of the Yucatan Peninsula. In: W. Lutz, L. Prieto, and W. Sanderson, eds. Population, Development, and Environment on the Yucatán Peninsula: From Ancient Maya to 2030. Laxenburg, Austria: International Institute for Applied Systems Analysis.

Wada, Y., 2016. Modeling Groundwater Depletion at Regional and Global Scales: Present State and Future Prospects. Surveys in Geophysics, 37 (2), 419-451.

World Economic Forum, 2016. The Global Risks Report 2016. 11th ed. Geneva: World Economic Forum. 
Table 1. Definition of processes for the groundwater balance.

Table 2. Data sources to obtain the groundwater balance.

Table 3. Summary of SDG 6 targets for global monitoring that can be addressed with the Local Groundwater Balance Model.

Figure 1. Location of the Geohydrological Reserve in Yucatan, Mexico.

Figure 2. Five steps for the development of the Local Groundwater Balance Model.

Figure 3. System analysis for the Municipality of Tecoh with all sectors. For definitions of the flow abbreviations see Supplementary Material.

Figure 4. Numerically solved water balance for the Geohydrological Reserve, Municipality of Tecoh 2014. For definitions of the flow abbreviations see Supplementary Material. 